\title{
Quality of life of post-menopausal women residing in rural and urban areas of Sikkim, India
}

\author{
Barkha Devi*, Prerna Karki, Rajnee Chhetry, Neelam Sharma, Manisha Niroula, \\ Pema Chuki Lepcha, Shobna Pradhan, Yanchen Sherpa, Anjali Sherpa, Priya Sharma, \\ Beenu Sharma, Khushboo Thapa, Bhawana Sharma, Tshring Y. Bhutia, Anney Singh Chib
}

Sikkim Manipal College of Nursing, Sikkim Manipal University, Gangtok, Sikkim, India

Received: 16 October 2018

Accepted: 12 November 2018

\section{*Correspondence:}

Ms. Barkha Devi,

E-mail: barkhadevi2@gmail.com

Copyright: (C) the author(s), publisher and licensee Medip Academy. This is an open-access article distributed under the terms of the Creative Commons Attribution Non-Commercial License, which permits unrestricted non-commercial use, distribution, and reproduction in any medium, provided the original work is properly cited.

\begin{abstract}
Background: Menopause is an inevitable reproductive phase during midlife when various physical and mental changes may impair the quality of life of women. The presence and severity of symptoms vary tremendously from woman to woman and can last from months to years during this transitional period. This study was conducted to assess the quality of life and menopause related problems among post-menopausal women residing rural and urban areas of Sikkim.

Methods: Descriptive explorative study was done in East Sikkim among 120 rural and urban post-menopausal women who were in the age group of 45 years and above, had attained natural menopause and didn't have menstruation from last one year, were selected through purposive sampling technique. Women with induced menopause, hysterectomy, receiving hormonal treatment were excluded. Along with collection of socio-demographic data, the Menopause Specific Quality of Life Questionnaire was used to assess the Quality of life based on experience of the symptoms through interview technique.

Results: The mean menopausal age was $48 \pm 3.649$ years in rural area and $47 \pm 3.831$ years for urban area. The mean scores in quality of life between post-menopausal women in rural areas $(\mathrm{M}=136.6, \mathrm{SD}=28.78)$ were found significantly impaired and the difference was found statistically significant $(t=5.75 \mathrm{p}<0.001)$ which shows that rural women were having impaired quality of life as compared to urban women during post-menopausal period. The findings also revealed that factors affecting the quality of life of postmenopausal women were the history of menopause, occupation of women, in urban women and time of attending menopause, in rural women.

Conclusions: The present study shows that menopause related symptoms had a negative effect on the quality of life of the post-menopausal women. Such studies can help in creating awareness and in educating women on the early identification of the common menopausal symptoms.
\end{abstract}

Keywords: Menopausal symptoms, Menopause, Postmenopausal women, Quality of life, Rural area, Urban area

\section{INTRODUCTION}

Aging is a natural process of maturation. All facts of aging are important to consider from a Women's health perspective. ${ }^{1}$ Women play an important role in replenishing the earth but her reproductive capacity is not permanent; it ceases one day which is coined as menopause. ${ }^{2}$ The term "menopause" means that meno (month) and pause (to end). Thus, the literal definition is the end of the cycle of monthly menstrual bleeding. ${ }^{3}$ Modern medicine has significantly prolonged the life span of humans and most women spend one-third to half 
of their lifetime in post- menopause. ${ }^{4}$ Information regarding experiences in menopause among different racial and ethnic groups should be given importance by healthcare personnel to provide appropriate and specific interventions..$^{5,6}$

In present era with increased life expectancy, women are likely to face long periods of menopause accounting to approximately a third of her life. While most women traverse the menopausal transition with little difficulty, others may undergo significant stress. The presence and severity of symptoms vary tremendously from woman to woman and can last from months to years during this transitional period. Menopausal symptoms have significant impact on quality of life of menopausal women at different status of menopause. ${ }^{7}$

During menopause, women often experience some symptoms which may affect their daily activities. Recent years, studies have shown that menopausal symptoms may affect health-related quality of life. ${ }^{8}$ It is observed that there is dietary and nutritional variation seen in rural and urban postmenopausal women. This affects the height weight and thus the body mass index in them. Studies have shown that the body mass index is more in the urban women than the rural postmenopausal women. ${ }^{9}$

The quality of life with the systemic illnesses affects the mobility of the individual. The level of activity differs in rural and urban population. The rural postmenopausal women were seen to be more active than the urban postmenopausal women. This was one of the reasons the body mass index was more in urban women due to their sedentary lifestyle and the nutritional habits. ${ }^{6}$ The educational level was also one of the factors contributing to the affection of the quality of life in the rural postmenopausal women than the urban women. There are more facilities and better infrastructures available for the urban population and the literacy level is also higher in urban population than rural population. Thus, the quality of life is better in urban than in rural postmenopausal women. ${ }^{5}$

Menopause, especially in a rural woman brings in lot of changes which she has to tackle to get rid of chronic illnesses especially psychosomatic problems. The efficient and effective means of preventing and controlling these problems is through improving social support, self-esteem, and empowerment. ${ }^{10}$

Sharadha $\mathrm{R}$ conducted a study on social support system among 56 middle-aged menopausal women residing in the rural areas of Chennai, Tamil Nadu and found that correlations were statistically significant with $\mathrm{P}<0.01$ in a two tailed test. ${ }^{11}$ Self-esteem was positively associated with social support $(\mathrm{r}=0.044)$, empowerment $(\mathrm{r}=0.354)$, and self-efficacy $(\mathrm{r}=0.566)$. The highest absolute correlation was found between loneliness and stress $(\mathrm{r}=716)$, depression and stress $\left(\mathrm{r}^{\wedge} 0.701\right)$ and social support with loneliness $(\mathrm{r}=0.646)$.
The study concluded that social support, self-esteem, empowerment, and psychosocial indicators have a correlation among menopausal women. The current national program on reproductive health focuses on women between 15 and 45 years of age and very less attention is being paid to women beyond reproductive age unless conditions become worse. The information on menopausal symptoms and the way women choose to treat these symptoms are essential for designing appropriate delivery of healthcare services and to ensure easy transition to old age. ${ }^{12}$

Problem statement: quality of life of post-menopusal women residing in rural and urban areas of Sikkim.

The study aimed to assess the quality of life of postmenopausal women residing in rural and urban areas; to compare the quality of life of post-menopausal women residing in rural and urban areas and to find out an association between quality of life of postmenopausal women with selected variables.

\section{Operational definitions}

Post-menopausal women

In this study, postmenopausal women refer to married, unmarried, employed or unemployed women at the age of 45 years and above, who have experienced 12 consecutive months of amenorrhea and who are not on hormone replacement therapy (HRT).

\section{Rural areas}

In this study, it refers to the selected rural areas which come under selected primary health center.

\section{Urban areas}

In this study, it refers to the selected areas which come under selected urban family welfare center.

\section{Quality of life}

In this study, quality of life refers to the way a woman overcomes significant one of four domains of menopausal symptoms, as experienced over the last month: Vasomotor (items 1-3), psychosocial (items 410), physical (items 11-26), and sexual (items 27-29) as assessed by menopause-specific quality of life questionnaire.

\section{Hypothesis}

All hypothesis measure at 0.05 level of significance.

$\mathrm{H}_{1}$ : There is a significant difference between the mean quality of life score of post-menopausal women in rural and urban areas at 0.05 level of significance. 
$\mathrm{H}_{2}$ : There is a significant association between the quality of life of post-menopausal women residing in rural and urban areas with selected variables at 0.05 level of significance.

\section{METHODS}

The purpose of this study is to assess and compare the difference in quality of life of post- menopausal residing in rural and urban areas of Sikkim in relation to menopausal symptoms.

This is a descriptive comparative study carried out at selected rural and urban areas of Gangtok, East Sikkim, India between the period of September 2017 to June 2018 to assess the quality of life of post-menopausal women.

\section{Inclusion criteria}

- 120 postmenopausal women (60 from each area) at the age of 45 years and above, had attained natural menopause, didn't have menstruation from last one year, residing in a selected rural and urban areas of Sikkim, and can understand and speak English, Hindi or Nepali were selected by non-probability purposive sampling technique from selected rural and urban areas of East Sikkim.

\section{Exclusion criteria}

- The exclusion criteria for sample was postmenopausal women with severe illness, bedridden, mentally challenged, on chemotherapy, induced menopause, hysterectomy and receiving any kind of hormone therapy.

The instrument used for data collection was a Standardized menopause specific quality of life questionnaire validated by five experts from Department of Obstetrics and Gynecology, Department of Psychiatric and Obstetrics and Gynecological nursing.

A standardized menopause specific quality of life questionnaire was selected as a tool for the study. The questionnaire was developed to collect data about sociodemographic profile framed under Standardized menopause specific quality of life questionnaire. The questionnaire was developed to collect data about background data, under section I as Part A consisted items of background data of the postmenopausal women age, marital status, educational status, occupational status, habitat, religion, parity, type of family, source of income, addiction and section II consisted of seven point rating scale with 29 items which indicate problem experienced by post-menopausal women in the past week and their rating depending upon the severity.

There is no right or wrong answer. Maximum score is 232 and minimum score is 29 . After an extensive review of literature and discussion with the experts, a standardized menopause specific quality of life questionnaire was prepared to assess the quality of life of postmenopausal women in rural and urban areas of East Sikkim.

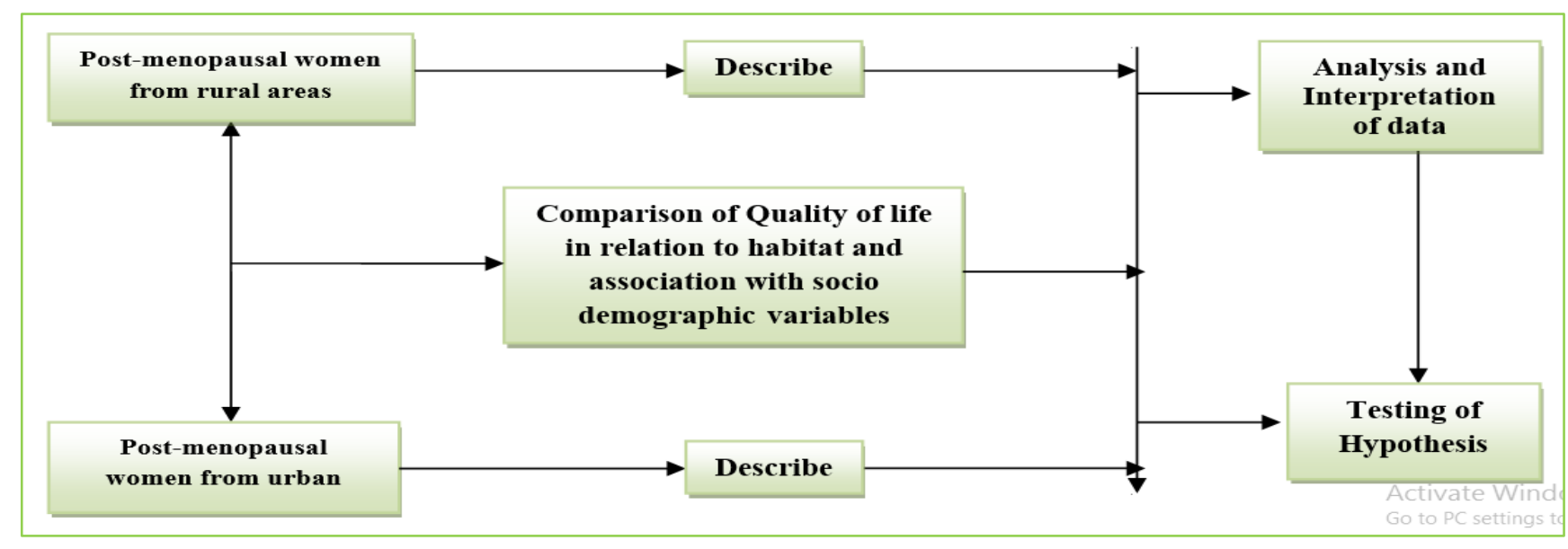

Figure 1: Schematic representation of descriptive comparative design.

The standardized menopause specific quality of life questionnaire was filled up by the investigator which were tested for its reliability by Cronbach's alpha method, for which the value of " $r$ " was found 0.83 which indicated a perfect reliability of the tool as reflected by high level of equivalence and socio demographic profile by intra-rater method.

Ethical permission was sought from institutional ethics committee and informed written consent was taken from 
all the participants. After explaining the purpose of the study, the administrative approval was taken, selfintroduction and establishment of rapport with the participants was done to gain their co-operation and after that the post-menopausal women were given the questionnaire.

\section{RESULTS}

Section I: Findings related to association between quality of life of post-menopausal women with their demographic variable in rural and urban area

Table 1: Association between quality of life of post-menopausal women with demographic variable $\mathrm{N}=120$.

\begin{tabular}{|c|c|c|c|c|c|c|}
\hline \multirow{3}{*}{ Selected variables } & \multicolumn{6}{|c|}{ Post-menopausal women } \\
\hline & \multicolumn{3}{|c|}{ Rural area, $n=60$} & \multicolumn{3}{|c|}{ Urban area, $n=60$} \\
\hline & df & $\chi^{2}$ & P-value & df & $\chi^{2}$ & P-value \\
\hline \multicolumn{7}{|l|}{ Age (in years) } \\
\hline$<55$ years & 1 & 0.01 & $\mathrm{P}>0.05$ & 1 & 3.53 & $\mathrm{P}>0.05$ \\
\hline \multicolumn{7}{|l|}{$>55$ years } \\
\hline \multirow{2}{*}{\multicolumn{7}{|c|}{$\begin{array}{l}\text { Marital status } \\
\text { Married }\end{array}$}} \\
\hline & & & & & & \\
\hline Unmarried & 4 & 4.63 & $\mathrm{P}>0.05$ & 4 & 2.87 & $\mathrm{P}>0.05$ \\
\hline \multicolumn{7}{|l|}{ Widow } \\
\hline \multicolumn{7}{|l|}{ Divorced } \\
\hline \multicolumn{7}{|l|}{ Education } \\
\hline No formal education & \multirow{3}{*}{4} & \multirow{3}{*}{1.94} & \multirow{3}{*}{$\mathrm{P}>0.05$} & \multirow{3}{*}{4} & \multirow{3}{*}{5.06} & \multirow{3}{*}{$\mathrm{P}>0.05$} \\
\hline Middle school & & & & & & \\
\hline Graduate & & & & & & \\
\hline Occupation of women & \multirow{3}{*}{1} & \multirow{3}{*}{3.78} & \multirow{3}{*}{$\mathrm{P}>0.05$} & & \multirow{3}{*}{4.3} & \multirow{3}{*}{$\mathrm{P}<0.05^{*}$} \\
\hline Housewife & & & & \multirow[t]{2}{*}{1} & & \\
\hline Working & & & & & & \\
\hline Occupation of husband & & & & & & \\
\hline Working in government & 1 & 378 & & & & \\
\hline Working in private & 4 & 3.78 & $P>0.05$ & 1 & 1.1 & $P>0.05$ \\
\hline Farmer & & & & & & \\
\hline Religion & & & & & & \\
\hline Hindu & 1 & 01 & D) 905 & 4 & 24 & D) 005 \\
\hline Christian & 4 & 0.4 & $P>0.05$ & 4 & 2.4 & $P>0.05$ \\
\hline Buddhist & & & & & & \\
\hline Parity & & & & & & \\
\hline Nulliparous & 2 & 0 & $\mathrm{P}>0.05$ & 1 & 1.9 & $\mathrm{P}>0.05$ \\
\hline Parous & & & & & & \\
\hline Type of family & & & & & & \\
\hline Nuclear & 1 & 1.54 & $\mathrm{P}>0.05$ & 1 & 0.004 & $\mathrm{P}>0.05$ \\
\hline Joint & & & & & & \\
\hline Source of income & & & & & & \\
\hline Spouse & 1 & 0.5 & $\mathrm{P}>0.05$ & 1 & 0.393 & $\mathrm{P}>0.05$ \\
\hline Children & & & & & & \\
\hline Income per month & & & & & & \\
\hline$>10,000$ & 1 & 0.5 & $\mathrm{P}>0.05$ & 1 & 0 & $\mathrm{P}>0.05$ \\
\hline$<10,000$ & & & & & & \\
\hline Addiction & & & & & & \\
\hline Nothing & 1 & & $P>005$ & 3 & 18 & $P>005$ \\
\hline Tobacco & 1 & 2.5 & $P>0.05$ & 3 & 1.8 & $P>0.05$ \\
\hline Smoking & & & & & & \\
\hline Age at menopause & & & & & & \\
\hline$>45$ & 0 & 1 & $\mathrm{P}>0.05$ & 1 & 0.6 & $\mathrm{P}>0.05$ \\
\hline$<45$ & & & & & & \\
\hline
\end{tabular}


The data reveals that majority of post-menopausal women that is $94 \%$ in rural and $82 \%$ in urban were married whereas 5\% were unmarried in urban area and $3 \%$ from rural areas and $13 \%$ were widow. Majority of the postmenopausal women from both rural $(73 \%)$ and urban $(87 \%)$ falls under the category of monogamy. In rural area $67 \%$ of post-menopausal women had no formal education and $18 \%$ know how to read and write. In urban area $25 \%$ of post-menopausal women had no formal education, as well as knows how to read or write. In rural $92 \%$ of women were housewife and only 5\% were working whereas in urban area $63 \%$ were housewife and rest $37 \%$ were working (Table 1 ). The data also reveals that majority of women $(78 \%)$ were Hindu in rural and $65 \%$ in urban area. All the women in rural area were found to be parous $(100 \%)$. In rural area majority of $32 \%$ of postmenopausal women had income 5001-7000 and in urban area 58\% has their monthly income 9001 and above. Majority of $57 \%$ postmenopausal women in rural area had no addiction and few $25 \%$ of them had addiction towards tobacco whereas $63 \%$ women had no any addiction and few $19 \%$ were addicted to smoking and $8 \%$ to tobacco in urban area (Table 1). The data shows that there was a significant association found between in occupation of women in urban and rural area $(\mathrm{P}<0.05)$ which shows that these variables influence the quality of life of post-menopausal women residing in rural area with these variables (Table 1).

Section II: Findings related to level of symptoms among post-menopausal women through menopause specific quality of life questionnaire in rural and urban area

The data depicts that (17\%) of urban women and (12\%) rural women experience mild. level of distress with the post-menopausal symptoms $(27 \%)$ of urban women and $(21 \%)$ of rural women experience relatively mild distress. (27\%) urban women and $(20 \%)$ rural women experience moderate level of distress whereas $(23 \%)$ of rural women and only $(16 \%)$ of urban women is experiencing relatively moderate distress. Only (17\%) of rural women and $(8 \%)$ of urban women had severe distress. Very few women $(7 \%)$ from rural and $(5 \%)$ from urban area had experienced extremely severe level of distress (Figure 2).

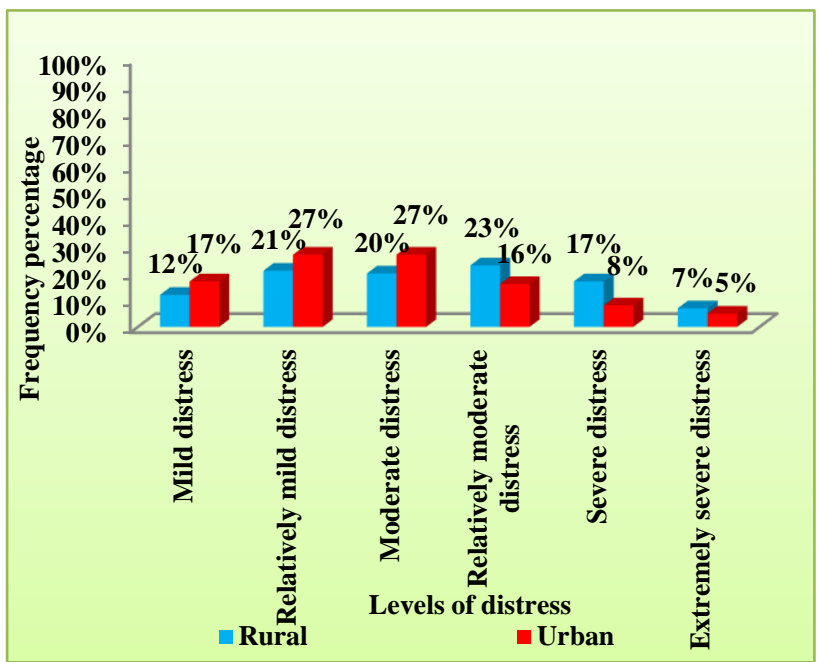

Figure 2: Difference in quality of life of postmenopausal women in terms of level of distress.

\section{Section III- Findings related to difference in quality of life of post-menopausal women residing in rural and urban area}

In terms of overall quality of life score of post-
menopausalwomen

The data shows that there is a significant difference in quality of life score between postmenopausal women who reside in urban areas and those who dwell in rural areas $(\mathrm{t}=5.75, \mathrm{P}<0.05,0.001)$. This indicates that residency work as a function which can influence the quality of life of postmenopausal women (Table 2).

Table 2: Difference in quality of life of post-menopausal women residing in rural and urban area $\mathrm{N}=120$.

\begin{tabular}{|c|c|c|c|c|c|}
\hline Area & Score & Mean & Mean difference & SD & ' $t$ ' value \\
\hline Rural & 8063 & 136.6 & \multirow{2}{*}{75.5} & 28.78 & \multirow{2}{*}{$5.75^{*}$} \\
\hline Urban & 7076 & 117.1 & & 29.8 & \\
\hline
\end{tabular}

$\mathrm{df}_{(118)}=1.98, \mathrm{P}<0.05$

In terms of area wise score in menopause specific quality of life questionnaire for post- menopausal women

In Table 3, it was found that postmenopausal women residing in rural area scored higher in all different dimensions of quality of life as compared to postmenopausal women residing in urban area. Thus, it indicates that rural postmenopausal women have symptoms of distress in menopausal phase as compared to postmenopausal women residing in urban area. The unpaired t-test shows that there is a significant difference in quality of life in terms of vasomotor symptoms $(t=5$, $\mathrm{P}<0.05)$, psycho-social symptoms $\quad(\mathrm{t}=3, \quad \mathrm{P}<0.05))$, physical symptoms $(\mathrm{t}=2.8, \quad \mathrm{P}<0.05) \quad$ and sexual symptoms $(\mathrm{t}=2.5, \quad \mathrm{P}<0.05)$ between postmenopausal women who reside in urban areas and those who dwell in rural areas. 
Table 3: Area wise mean assessment of quality of life by menopause specific quality of life questionnaire in rural and urban area.

\begin{tabular}{|c|c|c|c|c|c|}
\hline \multirow{3}{*}{$\begin{array}{l}\text { Area of quality of life by } \\
\text { menopause specific quality of } \\
\text { life questionnaire }\end{array}$} & \multicolumn{4}{|c|}{ Quality of life score for postmenopausal women } & \multirow{3}{*}{ ' $t$ ' test } \\
\hline & \multicolumn{2}{|c|}{ Rural, $n=60$} & \multicolumn{2}{|c|}{ Urban, $n=60$} & \\
\hline & Mean \pm SD & Mean \% & Mean \pm SD & Mean \% & \\
\hline Vasomotor & $13.7 \pm 4.9$ & 56.7 & $16.3 \pm 4.2$ & 48.6 & $5 *(P<0.05)$ \\
\hline Psycho-social & $31.3 \pm 8.47$ & 47.2 & $68.2 \pm 11.8$ & 27.0 & $3 *(\mathrm{P}<0.05)$ \\
\hline Physical & $75.6 \pm 17$ & 56 & $27.05 \pm 7.6$ & 50.9 & $2.8 *(\mathrm{P}<0.05)$ \\
\hline Sexual & $14.5 \pm 4.4$ & 57.2 & $12.3 \pm 3.71$ & 68.4 & $2.5 *(\mathrm{P}<0.05)$ \\
\hline
\end{tabular}

$\mathrm{df}_{(118)}=1.98, \mathrm{P}<0.05$

In terms of postmenopausal symptoms in relation to each domain in menopause specific quality of life questionnaire

The independent-samples t-test indicates that there is a significant difference found between sweating symptoms among rural post-menopausal women $(4.56 \pm 1.81)$ and urban post-menopausal women $(3.6 \pm 1.3),(\mathrm{t}=3.4, \mathrm{P}<0.05)$ (Table 4).
The independent-samples t-test indicates that there is a significant difference found between feeling a lack of energy symptoms $(\mathrm{t}=2.02, \mathrm{P}<0.05)$, dry skin symptoms $(\mathrm{t}=1.99, \mathrm{P}<0.05)$, increased facial hair symptoms $(\mathrm{t}=2.1$, $\mathrm{P}<0.05)$, feeling bloated symptoms $(\mathrm{t}=2.1, \mathrm{P}<0.05)$ and low backache $(\mathrm{t}=2.02, \quad \mathrm{P}<0.05)$ among rural postmenopausal women and urban post- menopausal women (Table 5).

Table 4: Compare the difference in presence of vasomotor symptoms among post-menopausal women in rural and urban area.

\begin{tabular}{|c|c|c|c|c|c|}
\hline \multirow{3}{*}{ Vasomotor symptoms } & \multicolumn{4}{|c|}{ Presence of postmenopausal symptoms among postmenopausal women } & \multirow{3}{*}{ ' $t$ ' test } \\
\hline & \multicolumn{2}{|c|}{ Rural area, $n=60$} & \multicolumn{2}{|c|}{ Urban area, $n=60$} & \\
\hline & Mean \pm SD & Mean \% & Mean \pm SD & Mean \% & \\
\hline Hot flushes & $4.8 \pm 1.8$ & 56.7 & $4.5 \pm 1.7$ & 66.7 & $0.9(\mathrm{P}>0.05)$ \\
\hline Night sweats & $4.43 \pm 1.86$ & 62 & $4.0 \pm 1.8$ & 58.2 & $0.74(\mathrm{P}>0.05)$ \\
\hline Sweating & $4.56 \pm 1.81$ & 64.5 & $3.6 \pm 1.3$ & 50.2 & $3.4 *(\mathrm{P}<0.05)$ \\
\hline
\end{tabular}

$\mathrm{df}_{(118)}=1.98, \mathrm{P}<0.05$

Table 5: Compare the difference in presence of physical symptoms among post-menopausal women in rural and urban area.

\begin{tabular}{|c|c|c|c|c|c|}
\hline \multirow{3}{*}{ Physical symptoms } & \multicolumn{4}{|c|}{$\begin{array}{l}\text { Presence of postmenopausal symptoms among } \\
\text { postmenopausal women }\end{array}$} & \multirow{3}{*}{ ' $t$ ' test } \\
\hline & \multicolumn{2}{|c|}{ Rural area, $n=60$} & \multicolumn{2}{|c|}{ Urban area, $n=60$} & \\
\hline & Mean \pm SD & Mean\% & Mean \pm SD & Mean\% & \\
\hline Flatulence (wind, gas pain) & $4.43 \pm 1.77$ & 70.5 & $3.9 \pm 1.8$ & 59 & $0.32(\mathrm{P}>0.05)$ \\
\hline Aching in muscle and joints & $5.05 \pm 1.74$ & 78.5 & $3.8 \pm 1.4$ & 70 & $0.29(\mathrm{P}>0.05)$ \\
\hline Feeling tired or worn out & $4.9 \pm 1.6$ & 79.2 & $4.1 \pm 1.5$ & 64 & $0.27(\mathrm{P}>0.05)$ \\
\hline Difficulty sleeping & $4.55 \pm 1.5$ & 72.5 & $4.1 \pm 1.5$ & 64.7 & $0.24(\mathrm{P}>0.05)$ \\
\hline Aches in back of neck or head & $4.66 \pm 3.14$ & 58.3 & $4.66 \pm 2.58$ & 58.3 & $0(\mathrm{P}>0.05)$ \\
\hline Decrease in physical strength & $3.7 \pm 1.78$ & 73.7 & $4.1 \pm 1.5$ & 67.5 & $0.59(\mathrm{P}>0.05)$ \\
\hline Decrease in stamina & $5.05 \pm 1.74$ & 73.5 & $3.2 \pm 1.4$ & 73.7 & $0.28(\mathrm{P}>0.05)$ \\
\hline Feeling a lack of energy & $4.75 \pm 2.02$ & 76 & $4 \pm 1.5$ & 75 & $2.02 *(\mathrm{P}<0.05)$ \\
\hline Dry skin & $5.2 \pm 1.66$ & 69.7 & $4.7 \pm 1.7$ & 66.5 & $1.99 *(\mathrm{P}<0.05)$ \\
\hline Weight gain & $4.85 \pm 1.49$ & 60 & $4.4 \pm 1.6$ & 55.7 & $1.75(\mathrm{P}>0.05)$ \\
\hline Increase facial hair & $5.16 \pm 1.91$ & 49.7 & $4.5 \pm 1.8$ & 30 & $2.1 *(\mathrm{P}<0.05)$ \\
\hline Changes in appearance, texture or tone of skin & $4.91 \pm 1.92$ & 55.7 & $4.7 \pm 1.7$ & 62.2 & $0.6(\mathrm{P}>0.05)$ \\
\hline Feeling bloated & $5.16 \pm 1.62$ & 47.5 & $4.6 \pm 1.5$ & 56.2 & $2.1 *(\mathrm{P}<0.05)$ \\
\hline Low backache & $4.96 \pm 1.52$ & 72.2 & $4.9 \pm 1.1$ & 66.5 & $3 *(\mathrm{P}<0.05)$ \\
\hline Frequent urination & $4.55 \pm 1.65$ & 65 & $5.0 \pm 1.2$ & 58.7 & $1.8(\mathrm{P}>0.05)$ \\
\hline Involuntary urination when laughing or coughing & $4.38 \pm 1.69$ & 63 & $4.5 \pm 1.7$ & 36.7 & $0.3(\mathrm{P}>0.05)$ \\
\hline
\end{tabular}

'df' (118) $=1.98, \mathrm{P}<0.05$ 
The independent-samples t-test indicates that there is a significant difference found between avoiding intimacy symptoms among rural post-menopausal women and urban post-menopausal women $(\mathrm{t}=8.46, \mathrm{P}<0.05)$ (Table $6)$.

The t-test indicates that there is a significant difference found between feeling anxious or nervous symptoms $(\mathrm{t}=4.4, \mathrm{P}<0.05)$, accomplishing less than $\mathrm{I}$ used to $(\mathrm{t}=2.8$, $\mathrm{P}<0.05)$, feeling depressed down or blue $(\mathrm{t}=2.17, \mathrm{P}<0.05)$ and feeling of wanting to be alone $(\mathrm{t}=5.6, \mathrm{P}<0.05)$, among rural post-menopausal women and urban postmenopausal women This indicates that there is a significant difference found between presences of postmenopausal symptoms in relation to area through menopause specific quality of life questionnaire (Table 7).

Table 6: Compare the difference in presence of sexual symptoms among post-menopausal women in rural and urban area.

\begin{tabular}{|c|c|c|c|c|c|}
\hline \multirow{3}{*}{ Sexual symptoms } & \multicolumn{4}{|c|}{$\begin{array}{l}\text { Presence of postmenopausal symptoms among } \\
\text { postmenopausal women }\end{array}$} & \multirow{3}{*}{ ' $t$ ' test } \\
\hline & \multicolumn{2}{|l|}{ Rural area, $n=60$} & \multicolumn{2}{|c|}{ Urban area, $n=60$} & \\
\hline & Mean \pm SD & Mean \% & $\operatorname{Mean} \pm$ SD & Mean \% & \\
\hline Change in your sexual desire & $4.71 \pm 1.85$ & 65.7 & $5.2 \pm 1.7$ & 80.7 & $1.6(\mathrm{P}>0.05)$ \\
\hline Vaginal dryness during intercourse & $5.06 \pm 1.77$ & 68 & $5.1 \pm 1.9$ & 76.5 & $0.1(\mathrm{P}>0.05)$ \\
\hline Avoiding intimacy & $4.81 \pm 1.79$ & 72.2 & $5.9 \pm 1.6$ & 89 & $8.4 *(\mathrm{P}<0.05)$ \\
\hline
\end{tabular}

$\mathrm{df}_{(118)}=1.98, \mathrm{P}<0.05$

Table 7: Compare the difference in presence of psychosocial symptoms among post-menopausal women in rural and urban area.

\begin{tabular}{|c|c|c|c|c|c|}
\hline \multirow{3}{*}{ Psychosocial symptoms } & \multicolumn{4}{|c|}{$\begin{array}{l}\text { Presence of postmenopausal symptoms among } \\
\text { postmenopausal women }\end{array}$} & \multirow{3}{*}{ ' $t$ ' test } \\
\hline & \multicolumn{2}{|c|}{ Rural area, $n=60$} & \multicolumn{2}{|c|}{ Urban area, $n=60$} & \\
\hline & Mean \pm SD & Mean \% & Mean \pm SD & Mean \% & \\
\hline Being dissatisfied with my personal life & $4.2 \pm 1.64$ & 57.2 & $3.98 \pm 1.74$ & 60.2 & $0.7(\mathrm{P}>0.05)$ \\
\hline Feeling anxious or nervous & $4.21 \pm 1.86$ & 75.5 & $2.8 \pm 1.8$ & 56 & $4.4 *(\mathrm{P}<0.05)$ \\
\hline Experiencing poor memory & $3.98 \pm 1.48$ & 78 & $4.2 \pm 1.5$ & 58 & $0.8(\mathrm{P}>0.05)$ \\
\hline Accomplishing less than I used to & $5.01 \pm 1.53$ & 67.7 & $4.03 \pm 1.7$ & 59.5 & $2.8 *(\mathrm{P}<0.05)$ \\
\hline Feeling depressed, down or blue & $4.85 \pm 1.78$ & 52.7 & $4.4 \pm 1.4$ & 50.7 & $2.17 *(\mathrm{P}<0.05)$ \\
\hline Being impatient with other people & $4.35 \pm 1.74$ & 65.2 & $4.2 \pm 1.9$ & 61 & $0.4(\mathrm{P}>0.05)$ \\
\hline Feeling of wanting to be alone & $4.36 \pm 1.60$ & 52.5 & $2.9 \pm 1.12$ & 45 & $5.6 *(\mathrm{P}<0.05)$ \\
\hline
\end{tabular}

$\mathrm{df}_{(118)}=1.98, \mathrm{P}<0.05$

\section{DISCUSSION}

The findings of the present study reveals that postmenopausal women in rural area shows symptoms like hot flushes $(85 \%)$, night sweat $(75 \%)$, aching in muscles and joints (95\%), feeling of lack of energy $(92 \%)$, ache in back of head and neck $(87 \%)$, weight gain $(83 \%)$, low back ache $(88 \%)$,avoiding intimacy $(80 \%)$, being impatient with others $(68 \%)$, feeling anxious or nervous $(60 \%)$. Postmenopausal women from the urban area shows symptoms like night sweats $(80 \%)$, Hot flushes $(83 \%)$, aches in back of neck or head $(93 \%)$, Decrease in stamina (98\%), weight gain (70\%), low backache $(68 \%)$, frequent urination $(73 \%)$, change in sexual desire $(87 \%)$, avoiding intimacy $(100 \%)$, and being impatient with others(83\%), however majority of the postmenopausal women showed symptoms as mentioned above. The findings of present study is consistent with the finding of the study of Satpathy M, who identified population comprised of menopausal women with hot flushes (77\%), sleep problem (42\%), joint pain (60), cold hand/feet $(27 \%)$, vagina dryness $(34 \%)$, weight gain $(69 \%)$, headache $(43 \%)$, irritability $(42 \%)$, forgetfulness $(59 \%)$, anxiety $(42 \%) .{ }^{13}$ This result is similar with study conducted Bansal et al, in which findings are headache (94.1\%), dizzy spells (81.5\%), decreased libido (81.5\%), sleep disturbance $(68.9 \%)$ and loss of interest in most things, hot flushes $(59.3 \%)$, lack of concentration $(54.1 \%)$, mood changes $(49.6 \%)$ and night sweats (35.6\%). ${ }^{14}$ Study conducted by Madhu Kumar and Gaikwad is similar with our study in which the results shows the symptoms like aching in muscle and joints, feeling tired, poor memory, lower backache. ${ }^{15}$ Similar study conducted by Borker et al, shows similar symptoms like depression, irritability ( 90.7\%), headache (72.9\%), lethargy $65.4 \%)$, dysuria $(58.9 \%)$, forgetfulness $(57 \%)$, musculoskeletal problems $(53.3 \%)$, sexual problems 
(decreased libido, dyspareunia) (31.8\%), genital problems (itching, vaginal dryness) $(9.3 \%) .{ }^{16}$ Symptoms like joint pain $(64 \%)$, backache $(58 \%)$, irritability $(56.66 \%)$, forgetfulness and sadness $(48 \%)$ and vasomotor symptoms like hot flushes and night sweats $(47.33 \%)$ are consistent with the study conducted by Sarker et al with present study. ${ }^{17}$ The findings of present study is consistent with the findings of the study of Sharma et al, who identified symptoms like fatigue and lack of energy $(72.93 \%)$, Headache $(55.9 \%)$, Hot flushes, Cold sweats, cold hand and feet $53.86 \%$, Weight gain $(43.13 \%) .{ }^{18}$ The findings of the present study reveals that postmenopausal women in a study conducted by Bagga A, in Pune shows common symptoms as compared to present study that is loss of interest $(93 \%)$, Pressure/tightness in head $(83 \%)$ Weight gain $(67 \%)$, Hot flushes $(54 \%) .{ }^{19}$ Muscle and joint pains $(37.4 \%)$, Insomnia $(20.6 \%)$, Headache $(13.8 \%)$ are shown in study conducted by Shah et al in Mumbai and diminished acuity of vision and hot flushes are shown in study conducted by Singh and Arora in Punjab is consistent with our present study. ${ }^{20}$

The present study findings show that the maximum quality of life score among post-menopausal woman was 27840. The quality of life score among postmenopausal women in urban area was 7076 the total score for rural area is 8063 which is slightly higher than the urban area which indicates that the quality of life of postmenopausal women of rural area were found to be distressing than that of urban area.

A cross sectional study conducted by Sharma $S$ and Mahajan $\mathrm{N}$ findings of the study were the high proportion $\mathrm{s}$ and the scores of MRS were observed in both rural and urban women. ${ }^{21}$ The severity of symptoms was found more distressing for rural women. The quality of life in urban society was average and better in rural women.

The present study findings show that among all variables has association between quality of life between urban and rural area. There is association in history of menopause in urban area and in rural area and there is association in physical activity during the year preceding menopause and also in time since attending menopause in urban area. A study conducted by Devi $S$ et al found that demographic variable, education of middle age women was found to have significant association with menopausal symptoms in rural women. ${ }^{19}$ None of the demographic variable was found to have significant association with menopausal symptoms in rural and urban women.

\section{CONCLUSION}

The present study results showed that various dimensions of quality of life were not at an acceptable level. There is a need to address the menopausal problem of postmenopausal women and establish health care centers for them. Postmenopausal women should be sensitized for availing the health facilities for their health problems by information education and communication (IEC) and behaviour change communication (BCC). Family support should be ensured by creating awareness in community. Awareness regarding menopause and problems among women related to it need to be improved. Health workers, ASHA, Aanganwadi workers can help women to understand about the menopausal symptoms, if they are given adequate training.

\section{Recommendations}

As per present study, there is a need to create awareness among the postmenopausal women about the physiology of menopause so that they can improve their quality of life. This awareness should be the earliest as women can cope with these symptoms to reduce the severity. Components related to specific health needs of postmenopausal women should be incorporated in the National Health Mission. Our study shows that postmenopausal women in rural area of East Sikkim suffer from various signs and symptoms, physical as well as vasomotor related to menopausal hormonal changes with varied frequencies, depending upon their demographic, contexts. There is a need to address the women group separately especially the disadvantaged rural subgroup, as there hasn't been a specific health program for those women yet.

From a public health perspective, there is considerable opportunity to improve postmenopausal women's quality of life by increasing health education about postmenopausal symptoms and its treatment by taking steps for life style modifications. Mild exercise should be encouraged and the avoidance of a sedentary lifestyle or living in isolation should be discouraged. This will help in coping with the challenges of this period.

\section{ACKNOWLEDGMENTS}

Authors would like to thank all the participants of the study for their kind cooperation.

\section{Funding: No funding sources \\ Conflict of interest: None declared}

Ethical approval: The study was approved by the Institutional Ethics Committee

\section{REFERENCES}

1. World Health Organization. Research on the menopause. 1981. World Health Organ Tech Rep Ser. 670:1-120.

2. Sharadha R. Social support system in menopause. Nightingale Nursing Times. 2009;5(6):12-1.

3. Wylie-Rosett J. Menopause, micronutrients, and hormone therapy. Am J Clin Nutr. 2005;81(5):1223S-31S.

4. World Health Organisation (WHO): Scientific Group on Research on the Menopause in the 1990s. Research on the menopause: Report of a WHO 
scientific group. WHO technical report series Geneva: WHO866; 1990.

5. Rotem M, Kushnir T, Levine R, Ehrenfeld M. A psycho-educational program for improving women's attitudes and coping with menopause symptoms. J Obstet Gynecol Neonatal Nurs. 2005;34(2):233-40.

6. Nusrat N, Nishat Z, Gulfareen H, Aftab M, Asia N. Knowledge, attitude and experience of menopause. J Ayub Med Coll Abbottabad. 2008;20(1):56-9.

7. Kawatkar S, Rairikar S, Shimpi A. Study of quality of life, body mass index and mobility in rural and urban post menopausal women. J Med Thesis. 2015;3(2):12-5.

8. Nisar N, Sohoo NA. Frequency of menopausal symptoms and their impact on the quality of life of women: a hospital based survey. J Pak Med Assoc. 2009;59(11):752-6.

9. Kuo Liu, Liu He, Xun Tang, Jinwei Wang, Na Li, Yiqun $\mathrm{Wu}$, et al. Relationship between menopause and health-related quality of life in middle-aged Chinese women: a cross-sectional study. BMC Women's Health. 2014;14(7).

10. Karmakar N, Majumdar S, Dasgupta A, Das S. Quality of life among menopausal women: A community-based study in a rural area of West Bengal. J Midlife Health. 2017;8(1):21-7.

11. World Health Organization. Research on menopause. Technical Report Series. 1981; 671:1-120.

12. Postmenopausal Cysto-urethritis. Available at: http://www.patient.co.uk/ doctor/ PostmenopausalCystourethritis.htm.

13. Satpath M. A study on age at menopause, menopausal symptoms and problems among urban women from western Odisha, India. Int J Sci Res Publ. 2016;6(3).

14. Bansal P, Chaudhary A, Soni RK, Sharma S, Gupta VK, Kaushal P. Depression and anxiety among middle-aged women: A community-based study. J Family Med Prim Care. 2015;4(4):576-81.
15. Madhukumar S, Gaikwad V, Sudeepa D. A community based study on perceptions about menopausal symptoms and quality of life of postmenopausal women in Bangalore rural. Int $\mathbf{J}$ Health Sci Res. 2012;2(3):49-56.

16. Borker SA, Venugopalan PP, Bhat SN. Study of menopausal symptoms, and perceptions about menopause among women at a rural community in Kerala. J Mid-life Health. 2013;4(3):182-7.

17. Amrita S, Pradeep P, Kakoli G, Sudip B, Naresh M, Sudha Y, et al. A study on health profile of postmenopausal women in Jamnagar district, Gujarat. J Res Med Dental Sci. 2017;2(2):25-9.

18. Bairy L, Adiga S, Parvathi BH, Rajeshwari BH. Prevalence of menopausal symptoms and quality of life after menopause in women from South India. Aus New Zealand J Obstet Gynaecol. 2009;49(1):106-9.

19. Devi S, Upendra S, Chavan R, Barde S. Assessment of menopausal symptoms using modified menopause rating scale (mrs) among middle age women in selected urban and rural area of Pune district. J Adv Sci Res. 2015;6(3):47-50.

20. Shah. Impact of post menopausal symptoms on quality of life on menopausal women and its outcomes. J Women Health. 2013.

21. Sharma S, Mahajan N. Menopausal symptoms and its effect on quality of life in urban versus rural women: A cross-sectional study. J Mid-Life Health. 2015;6(1):16.

Cite this article as: Devi $\mathrm{B}$, Karki $\mathrm{P}$, Chhetry R, Sharma N, Niroula M, Lepcha PC. Quality of life of post-menopausal women residing in rural and urban areas of Sikkim, India. Int J Reprod Contracept Obstet Gynecol 2018;7:5125-33. 